\title{
Método de cálculo de velocidade de motocicleta com base na distância de projeção do motociclista
}

\author{
Motorcycle speed calculation method based on motorcyclist projection distance
}

\author{
Manoel José Rodrigues Martins ${ }^{1}$, Alice Ferreira dos Santos de Oliveira ${ }^{2}$, Luiz Alberto Martins de \\ Oliveira $^{1}$, Juliano de Andrade Gomes ${ }^{*}$ \\ ${ }^{1}$ Polícia Civil do Distrito Federal, Instituto de Criminalística, Brasília, DF, Brasil. \\ ${ }^{2}$ Universidade de Brasília, Instituto de Física, Brasília, DF, Brasil.
}

Recebido em 24 de maio de 2020. Revisado em 07 de julho de 2020. Aceito em 14 de julho de 2020.

\begin{abstract}
O uso de motocicletas como um meio de transporte tem aumentado muito ultimamente; infelizmente, o número de acidentes envolvendo motociclistas também cresceu. Nesses casos, o papel do perito criminal é reconstruir a dinâmica do evento, devendo, entre outras coisas, determinar a velocidade dos veículos envolvidos. Este trabalho consiste na proposição de um método de cálculo de velocidades de motocicletas envolvidas em acidentes de trânsito nos casos em que ocorre a projeção do motociclista. Para isso, busca-se determinar a velocidade na qual o corpo do motociclista é projetado. No procedimento, a distância total de projeção é dividida em duas fases: voo e deslizamento. O cálculo do tempo de queda do corpo durante a fase de voo foi feito sem aproximações e, na fase de deslizamento, foi incluído o ângulo de inclinação do terreno. Após a obtenção da equação da velocidade de projeção do corpo do motociclista, é deduzida uma equação para o cálculo da velocidade desenvolvida pela motocicleta no instante da colisão. Por fim, considerando-se as margens de incertezas inerentes aos processos de medição das variáveis de entrada, foi empregado o método de Monte Carlo para analisar casos reais e avaliar o intervalo de confiança do resultado encontrado.
\end{abstract}

Palavras-chave: Perícia Criminal, Física Forense, Reconstrução de acidente de trânsito, Motociclista, Cálculo da velocidade.

The use of motorcycles as a means of transport has intensified a lot lately; unfortunately, the number of accidents involving motorcyclists has also increased. In such cases, the role of the forensic scientist is to reconstruct the dynamics of the event, and must, among other things, determine the speed of the vehicles involved. This work consists of proposing a method for calculating the speed of motorcycles involved in traffic accidents in cases where the projection of the rider occurs. To do this, the aim is to determine the speed with which the rider's body is designed. In the procedure, the total projection distance is divided into two phases: flight and slip. The calculation of the body's fall time during the flight phase was made without approximations and, in the slip phase, the slope angle of the terrain was included. After obtaining the equation of the projection speed of the rider's body, an equation is deduced to calculate the speed developed by the motorcycle at the collision time. Finally, considering the uncertainty margins inherent to the measurement processes of the input variables, the Monte Carlo method was applied to analyze real cases and to evaluate the confidence interval of the result found.

Keywords: Forensic Science, Forensic Physics, Traffic accident reconstruction, Motorcyclist, Speed calculation.

\section{Introdução}

De acordo com um relatório da Organização Pan-Americana da Saúde (OPAS), mais da metade das mortes no trânsito ocorre entre os chamados usuários vulneráveis das vias, que são os pedestres, os ciclistas e os motociclistas $[1]$.

Levando-se em conta os aspectos criminais decorrentes da legislação de trânsito brasileira, em especial o Código de Trânsito Brasileiro (CTB) e do Código de Processo Penal (CPP), do ponto de vista de perícia criminal [2] é

*Endereço de correspondência: perito.juliano@gmail.com importante desenvolver diferentes tipos de metodologias para investigar estes eventos [3-6].

Nos casos de colisão de veículos contra pedestres ou ciclistas, na maioria das vezes, o corpo do pedestre ou do ciclista é projetado à frente [7-9]. Do mesmo modo, nos casos em que motocicletas colidem contra objetos rígidos, quase sempre os ocupantes são projetados [8].

Para a análise pericial destes casos, há várias metodologias empregadas na determinação da velocidade de lançamento do corpo. Em geral, estas metodologias dependem da distância entre o ponto de lançamento e o ponto em que o corpo projetado toca o solo pela primeira vez $[8,10,11]$. Há casos em que o ponto de repouso final atingido pelo corpo projetado é bem determinado e, do 
mesmo modo, o ponto da colisão na pista. Nestes casos, a distância entre estes dois pontos pode ser empregada no cálculo da velocidade de projeção do corpo lançado [8].

Na abordagem do trabalho que está sendo proposto, a velocidade de projeção do corpo do motociclista é determinada com base na distância medida na pista entre o ponto da colisão e o ponto de repouso final atingido pelo corpo do motociclista. São necessários também o valor do coeficiente de atrito entre o corpo e o solo, o ângulo de lançamento e a altura em que se encontrava o centro de massa do corpo no momento do lançamento.

No presente artigo, o cálculo do tempo de queda do corpo durante a fase de voo foi feito de forma precisa, sem aproximações e, a fim de generalizar a abordagem, foi incluído na fase de deslizamento o ângulo de inclinação do terreno.

\section{Metodologia}

No primeiro momento buscou-se descrever, utilizandose dos conceitos de Mecânica Clássica, o movimento realizado pelo corpo projetado. Este percurso é composto por duas fases: a fase de voo e a fase de deslizamento, conforme ilustrado na Figura 1. Durante a fase de voo, o corpo percorre uma trajetória parabólica e, após atingir o solo, percorre um trecho em deslizamento/arrastamento até atingir o repouso.

A abordagem foi feita buscando-se encontrar equações que fornecessem a distância percorrida pelo corpo durante a fase de voo, doravante denominada $S_{1}$, e a distância percorrida em deslizamento, doravante denominada $S_{2}$, ambas medidas sobre o solo e expressas em função da velocidade de lançamento [12]. A seguir, foi feita a soma destas duas distâncias obtendo-se a distância total de projeção $S_{t}$. A partir desta soma, obteve-se uma equação de quarto grau (equação bi quadrática), que não depende das distâncias individuais e que uma de suas soluções é a velocidade de lançamento do corpo.

Para descrever a fase do impacto, compartilhamos da ideia desenvolvida por Montenegro [10] onde, para representar o conjunto motociclista/motocicleta, considerou-se um modelo físico simplificado composto por dois blocos sobrepostos. Nesse modelo, o bloco inferior colide contra um objeto fixo ao solo e o bloco superior vence a força de atrito existente entre eles por inércia e é projetado à frente.

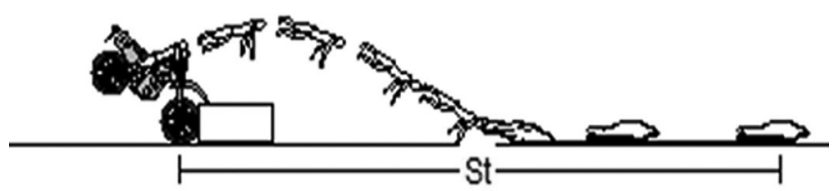

Figura 1: Representação esquemática do lançamento de um corpo
Posteriormente, a fim de obter a velocidade na qual a motocicleta colide com o obstáculo, foi necessário incluir a transferência de energia entre o corpo do motociclista e a estrutura da motocicleta, chegando no modelo final proposto neste trabalho.

Por fim, o modelo proposto foi aplicado em dois casos reais de acidentes de trânsito envolvendo motocicletas, os quais possuíam imagens de Circuito Fechado de Televisão (CFTV) que permitiram determinar, com razoável precisão, o valor da velocidade com que trafegava a motocicleta no instante da colisão com o veículo.

\section{Desenvolvimento Matemático}

A Figura 2 representa a trajetória percorrida pelo corpo do motociclista após o lançamento e auxilia na obtenção da equação que permite calcular a velocidade na qual ele foi projetado. As variáveis e os respectivos símbolos utilizados são:

- $\mathrm{S}_{\mathrm{t}}=\mathrm{S}_{1}+\mathrm{S}_{2}$ - distância total de projeção;

- $\mathrm{h}_{0}$ - altura do centro de massa do corpo no momento do lançamento;

- $\theta$ - ângulo de lançamento;

- $\alpha$ - ângulo de inclinação do terreno;

- $\mu$-coeficiente de atrito/arraste entre o corpo e o solo;

- $v$ - velocidade do centro de massa do corpo no momento do lançamento.

As equações horárias [13] que governam o movimento vertical realizado pelo corpo durante o movimento parabólico na fase de voo é:

$$
\begin{gathered}
y(t)=h_{0}+v_{0 y} t-\frac{1}{2} g t^{2} \\
x(t)=x_{0}+v_{0 x} t
\end{gathered}
$$

Adotando a origem do sistema de eixos conforme mostrado na Figura 2, podemos fazer $x_{0}=0$. Isolando $t$ na Equação 2 e substituindo na Equação 1, teremos:

$$
y(x)=h_{0}+\operatorname{tg} \theta x-\frac{g x^{2}}{2 v_{0 x}^{2}}
$$

Observando a Figura 2, vemos que $x_{1}$ é a distância horizontal que o corpo percorre na fase de voo e $h_{1}$ é

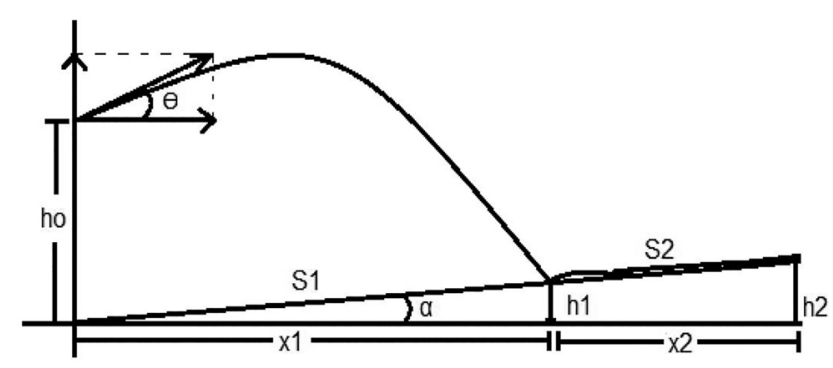

Figura 2: Variáveis relacionadas ao lançamento de um corpo 
a altura em que ele atinge o solo ao final desta fase. Estas duas variáveis podem ser escritas em termos do parâmetro $S_{1}$ da seguinte maneira:

$$
\begin{aligned}
& x_{1}=S_{1} \cos \alpha \\
& h_{1}=S_{1} \operatorname{sen} \alpha
\end{aligned}
$$

Observando-se a Equação 3 e a Figura 2, verifica-se que:

$$
y\left(x_{1}\right)=h_{1}
$$

Isto é:

$$
h_{1}=h_{0}+\operatorname{tg} \theta x_{1}-\frac{g x_{1}^{2}}{2 v_{0 x}^{2}}
$$

Substituindo-se os valores de $h_{1}$ (Equação 4 ) e $x_{1}$ (Equação 5) na Equação 7 e agrupando os termos, chegase a:

$$
S_{1}^{2}+\frac{2(\operatorname{tg} \alpha-\operatorname{tg} \theta) v_{0 x}^{2}}{g \cos \alpha} S_{1}-\frac{2 h_{0} v_{0 x}^{2}}{g(\cos \alpha)^{2}}=0
$$

A solução positiva da Equação 8 é a distância de voo $S_{1}$ e sobre ela recai o interesse pericial, isto é:

$$
S_{1}=\frac{\sqrt{(t g \alpha-t g \theta)^{2} v_{0 x}^{4}+2 g h_{0} v_{0 x}^{2}}}{g \cos \alpha}-\frac{(t g \alpha-t g \theta)}{g \cos \alpha} v_{0 x}^{2}
$$

Depois que atinge o solo, o corpo se desloca em deslizamento/arrastamento e/ou rolamento por uma distância $S_{2}$ até alcançar sua posição de repouso final. A distância $S_{2}$ pode ser obtida com o auxílio da equação de Torricelli:

$$
\begin{gathered}
0=v_{0 x}^{2}-2 a S_{2} \\
S_{2}=\frac{v_{0 x}^{2}}{2 a}
\end{gathered}
$$

Para determinar a aceleração, $a$ considerando a inclinação do terreno, deve-se observar que a fase de deslizamento se processa sobre um plano inclinado e, neste caso, a força que atua no sentido de alterar o estado de movimento do corpo é resultante da soma de duas forças: a componente do peso, $m g \operatorname{sen} \alpha$, e a força de atrito, $\mu m g \cos \alpha$. Aplicando a segunda lei de Newton, temos:

$$
\begin{gathered}
m a=m g \operatorname{sen} \alpha+\mu m g \cos \alpha \\
a=(\operatorname{sen} \alpha+\mu \cos \alpha) g
\end{gathered}
$$

Substituindo na Equação 11, teremos:

$$
S_{2}=\frac{v_{0 x}^{2}}{2 g(\operatorname{sen} \alpha+\mu \cos \alpha)}
$$

Na Equação 14, $\mu$ é o coeficiente de atrito/arraste entre o corpo e o solo, que pode ser de deslizamento, de rolamento ou da composição de ambos os movimentos, a depender da situação em análise.

De posse das distâncias $S_{1}$ e $S_{2}$, pode-se obter a distância total de projeção $S_{t}$, isto é:

$$
S_{1}+S_{2}=S_{t}
$$

Que pode ser escrita como:

$$
\begin{aligned}
& \frac{\sqrt{(t g \alpha-t g \theta)^{2} v_{0 x}^{4}+2 g h_{0} v_{0 x}^{2}}}{g \cos \alpha}-\frac{(t g \alpha-\operatorname{tg} \theta)}{g \cos \alpha} v_{0 x}^{2} \\
& +\frac{v_{0 x}^{2}}{2 a}=S_{t}
\end{aligned}
$$

Agrupando-se os termos, chega-se à igualdade expressa na equação abaixo:

$$
\begin{aligned}
& 2 a \sqrt{(\operatorname{tg} \alpha-\operatorname{tg} \theta)^{2} v_{0 x}^{4}+2 g h_{0} v_{0 x}^{2}}=2 a g \cos \alpha S_{t} \\
& +[2 a(\operatorname{tg} \alpha-\operatorname{tg} \theta)-g \cos \alpha] v_{0 x}^{2}
\end{aligned}
$$

Elevando os dois lados desta igualdade ao quadrado e desenvolvendo, chega-se ao seguinte resultado:

$$
\begin{aligned}
& {[4(\operatorname{tg} \alpha+\mu)(\operatorname{tg} \alpha-\operatorname{tg} \theta)-1] v_{0 x}^{4}+\left\{8 g h_{0}(\operatorname{tg} \alpha+\mu)^{2}\right.} \\
& -4 g S_{t}(\operatorname{sen} \alpha+\mu \cos \alpha)[2(\operatorname{tg} \alpha+\mu)(\operatorname{tg} \alpha-\operatorname{tg} \theta) \\
& -1]\} v_{0 x}^{2}-\left[2 g S_{t}(\operatorname{sen} \alpha+\mu \cos \alpha)\right]^{2}=0
\end{aligned}
$$

Observando-se a Equação 18, verifica-se que se trata de uma equação de quarto grau em relação a $v_{0 x}$, do tipo:

$$
A v_{0 x}^{4}+B v_{0 x}^{2}+C=0
$$

Isto é, uma equação bi quadrática com:

$$
\begin{aligned}
& A=4(\operatorname{tg} \alpha+\mu)(\operatorname{tg} \alpha-\operatorname{tg} \theta)-1 \\
& B=8 g h_{0}(\operatorname{tg} \alpha+\mu)^{2}-4 g S_{t}(\operatorname{sen} \alpha+\mu \cos \alpha) \\
& \times[2(\operatorname{tg} \alpha+\mu)(\operatorname{tg} \alpha-\operatorname{tg} \theta)-1] \\
& C=-\left[2 g S_{t}(\operatorname{sen} \alpha+\mu \cos \alpha)\right]^{2}
\end{aligned}
$$

As raízes desta equação podem ser obtidas considerandose $v_{0 x}^{2}=x$. Fazendo isso, chega-se a:

$$
A x^{2}+B x+C=0
$$

Cujas raízes são:

$$
\begin{aligned}
& x^{\prime}=\frac{-B-\sqrt{B^{2}-4 A C}}{2 A} \\
& x^{\prime \prime}=\frac{-B+\sqrt{B^{2}-4 A C}}{2 A}
\end{aligned}
$$

$\mathrm{E}$ as soluções para as velocidades são:

$$
\begin{aligned}
& v_{0 x}^{\prime}= \pm \sqrt{x^{\prime}} \\
& v_{0 x}^{\prime \prime}= \pm \sqrt{x},
\end{aligned}
$$

As Equações 23 e 24 correspondem às quatro raízes da Equação 18. Analisando-se estas equações, verifica-se que as soluções $v_{0 x}^{\prime}=-\sqrt{x}$ e $v_{0 x}^{\prime \prime}=-\sqrt{x^{\prime \prime}}$ devem ser desprezadas porque são incompatíveis com a realidade física, já que o sinal negativo que as acompanha indica o sentido do movimento e, considerando-se o sistema de referência adotado na Figura 2, o corpo percorreria 
primeiro o trecho de deslizamento e depois o trecho de voo.

A solução $v_{0 x}^{\prime}=+\sqrt{x^{\prime}}$ também deve ser desprezada, pois ao inserir nas Equações 9 e 14 os valores de velocidades fornecidos por ela, verifica-se que a soma das distâncias $S_{1}$ e $S_{2}$ é diferente de $S_{t}$. Esta constatação foi feita programando-se as Equações 9 e 14 em uma planilha eletrônica de cálculo e inserindo-se os referidos valores. Por outro lado, a solução $v_{0 x}^{\prime \prime}=+\sqrt{x}^{\prime \prime}$ é compatível com o sentido do deslocamento do corpo e os valores de velocidade que ela fornece são tais que a soma $S_{1}+S_{2}$ é exatamente igual a $S_{t}$. Logo, esta é a solução correta para a velocidade de lançamento do corpo, isto é:

$$
v_{0 x}=\frac{-B+\sqrt{B^{2}-4 A C}}{2 A}
$$

Esse resultado pode parecer muito trabalhoso para ser utilizado na prática, mas, programando-o em uma planilha eletrônica de cálculo, tem-se uma ferramenta de grande auxílio para o perito em trabalha com reconstrução de acidentes de trânsito desta natureza.

Como se vê, no caso de terrenos planos, são necessárias apenas três medidas: a altura em que o centro de massa do corpo se encontrava no início da projeção, a distância horizontal entre o ponto de projeção e o ponto de repouso final atingido pelo corpo, bem como o ângulo de lançamento [10].

Destacamos aqui que, entre os vários autores que se envolveram com o tema da projeção de corpos em eventos de acidentes de trânsito, seja a projeção de pedestres ou de ciclistas envolvidos em atropelamento, há sugestões de diferentes valores para o coeficiente de atrito, ficando bem evidente que cada autor, conforme o método que propõe, sugere um valor para esta grandeza $[7,8,14,15]$. De acordo a literatura $[7,16]$, os valores de coeficientes de atrito para arrastamento de pedestres em asfalto ficam compreendidos na seguinte faixa: $0,8 \leq \mu \leq 1,2$. Ressaltamos que esta faixa pode variar conforme as vestes do motociclista e as superfícies com as quais fizer contato durante a fase de deslizamento. Quanto ao ângulo $\theta$, há trabalhos $[8,17]$ que sugerem valores entre $10^{\circ}$ e $15^{\circ}$ para o lançamento do corpo do motociclista. Há autores que se aprofundaram no tema e examinaram imagens de vários acidentes registrados por sistemas de câmeras e sugerem valores entre $15^{\circ}$ e $17^{\circ}[8]$. Naturalmente, estes valores também podem variar e dependerão do caso prático em análise. Concordamos com a posição defendida por diversos autores quando afirmam que a determinação destas duas grandezas é a principal fonte de incerteza nos diversos métodos de projeção de corpos [10]. Entretanto, para contornar este fato, destacamos a importância e a robustez do método de simulação de Monte Carlo.

As equações desenvolvidas no presente estudo foram programadas em uma planilha eletrônica de cálculo na qual foi empregado o método de simulação de Monte Carlo $[18,19]$. Nesta planilha, para cada variável de entrada são gerados 30.000 valores aleatórios compreendidos no intervalo de incerteza admitido para esta variável. A distribuição utilizada para todas as variáveis foi a distribuição uniforme. Nessa distribuição, qualquer valor dentro do intervalo considerado tem sempre a mesma probabilidade de ocorrência. Os valores produzidos são inseridos nas equações do método que está sendo proposto e são realizados 30.000 cálculos de velocidades. O intervalo compreendido entre o menor e o maior valor de velocidade produzido é dividido em 20 fatias iguais (classes) e a cada classe é associada uma frequência de ocorrência dos valores de velocidade fornecidos pelo método. Por fim, uma curva de velocidade $\mathrm{x}$ frequência de ocorrência é plotada. Analisando-se a curva produzida, verifica-se que, para determinadas faixas de incerteza admitidas nas variáveis de entrada, esta curva tende naturalmente para uma curva normal (gaussiana). Assim, extraindo-se a média dos 30.000 valores de velocidade fornecidos e o respectivo desvio padrão, pode-se admitir um intervalo de confiança para o resultado encontrado. Nestas condições, considerando-se o intervalo de resultados correspondente a três desvios padrões, pode-se associar um nível de certeza de 99,73\% para o resultado fornecido pelo método que está sendo proposto no presente estudo.

Chamamos a atenção para o fato de que, na prática, a certeza do resultado conforme apontado acima depende do nível de certeza que pode ser associado às variáveis de entrada.

\subsection{Projeção de motociclistas}

A Figura 1 representa um evento típico em que uma motocicleta colide contra um objeto fixo ao solo e o motociclista é projetado à frente. Nos instantes imediatamente anteriores à colisão, a velocidade desenvolvida pelo conjunto motociclista/motocicleta é a mesma. Entretanto, quando ocorre o impacto, a motocicleta fica submetida a um processo de intensa desaceleração e as forças que garantem a estabilidade do motociclista sobre ela tendem a ser superadas, já que, de acordo com a lei da inércia, o estado de movimento do corpo do motociclista tende a ser preservado [13]. Nesse processo, outro evento esperado é o fato de a motocicleta inclinar-se para a frente, tendendo a girar em torno do eixo de sua roda anterior $[8,10]$. Assim, se a velocidade desenvolvida pelo conjunto não é muito reduzida, inevitavelmente o motociclista desprenderá da motocicleta e será projetado à frente.

Todavia, não se pode ignorar o fato de que esse processo de desprendimento do motociclista é quase sempre acompanhado da transferência de alguma quantidade de energia do corpo dele para a estrutura da motocicleta. Esta dissipação de energia é constatada, em geral, nos danos causados na motocicleta, como empenamento do guidão, marcas de fricção e amassamento no tanque de combustível, quebramento de carenagens, etc.

No presente estudo, decidimos por incluir esta energia nos cálculos e, para estimá-la, aplicamos o princípio da 
conservação da energia ao processo de desprendimento do motociclista. Fazendo isso, a energia dissipada pode ser estimada em termos de uma velocidade de danos. Esta velocidade de danos seria a velocidade que um corpo flácido de massa igual à massa do corpo do motociclista deveria desenvolver para causar na motocicleta os danos constatados, estando a motocicleta em repouso.

Destacamos, entretanto, que, assim como em outros métodos de cálculo de velocidades, trata-se de uma aproximação e, portanto, deve ser usada com base na experiência e com bastante cautela. Caso haja colisão entre o corpo do motociclista e outros objetos ou anteparos durante o processo de desprendimento, o método somente poderá oferecer a velocidade com a qual o corpo do motociclista inicia a fase de voo livre e não a velocidade desenvolvida pela motocicleta nos instantes imediatamente anteriores à colisão.

Aplicando o princípio da conservação da energia ao movimento realizado pelo corpo do motociclista durante o desprendimento, temos:

$$
E_{\text {imed. ant. col. }}=E_{\text {danos }}+E_{\text {após col. }}
$$

A energia efetivamente significativa é a energia cinética. Com isso, a Equação 24 pode ser escrita da seguinte maneira:

$$
\frac{1}{2} m v_{i}^{2}=\frac{1}{2} m v_{d}^{2}+\frac{1}{2} m v_{0 x}^{2}
$$

Que leva a:

$$
v_{i}^{2}=v_{d}^{2}+v_{0 x}^{2}
$$

Por fim, a:

$$
v_{i}=\sqrt{v_{d}^{2}+v_{0 x}^{2}}
$$

Que pode ser escrita como:

$$
v_{i}=\sqrt{v_{d}^{2}+\frac{\sqrt{B^{2}-4 A C}}{2 A}-\frac{B}{2 A}}
$$

Este modelo, apesar de carregar algum grau de subjetividade, permite ao perito avaliar a influência que os danos causados pelo corpo do motociclista na estrutura da motocicleta durante o processo de desprendimento exercem no resultado da velocidade desenvolvida por ambos nos instantes imediatamente anteriores à colisão.

\section{Estudo de Casos Reais}

Caso 01: A Figura 3 representa uma situação bastante comum na prática pericial. O veículo adentra a região do cruzamento e é atingido pela motocicleta, que trafegava pela via preferencial. No caso em análise, a velocidade desenvolvida pelo veículo no momento da colisão era reduzida (inferior a $30 \mathrm{~km} / \mathrm{h}$ ). A velocidade desenvolvida pela motocicleta nos instantes imediatamente anteriores à colisão foi calculada, com base em imagens de CFTV recolhidas nas proximidades do local do acidente, e chegou-se a um valor da ordem de $65 \mathrm{~km} / \mathrm{h}$.

Os dados utilizados para o cálculo da velocidade da motocicleta pelo método que está sendo proposto são:

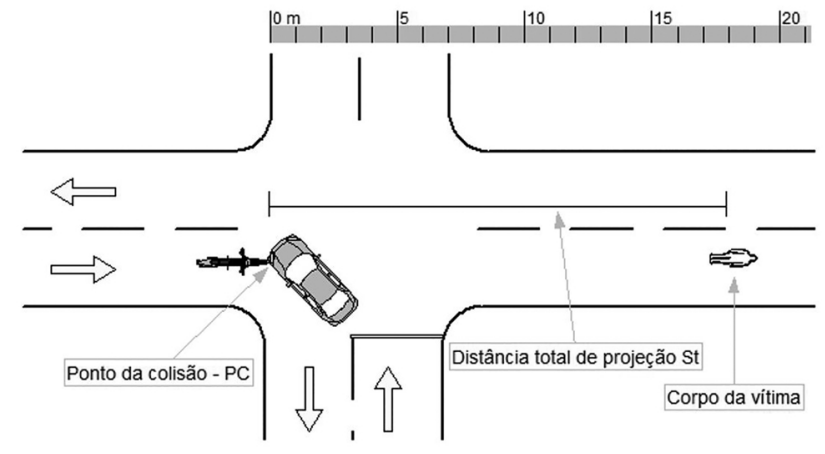

Figura 3: Esquema representativo de uma colisão envolvendo motocicleta e veículo com a projeção do corpo do motociclista (Caso 01)

- Altura do centro de massa do motociclista no momento do lançamento: $h_{0}=0,90 \pm 0,05 \mathrm{~m}$ (dado estimado em função da altura da motocicleta, medido no local, e da altura do motociclista, obtido no Instituto Médico Legal);

- Distância total de projeção do motociclista: $S_{t}=$ $18,0 \pm 0,5 m$ (medido no local do acidente por peritos criminais);

- Ângulo de lançamento: $\theta=12,5^{\circ} \pm 2,5^{\circ}$ (de acordo com dados da literatura $[8,17]$, oscila entre $10^{\circ} \mathrm{e}$ $\left.15^{\circ}\right)$

- Ângulo de inclinação do terreno: $\alpha=0,0^{\circ} \pm 0,0^{\circ}$ (medido no local do acidente por peritos criminais);

- Coeficiente de atrito: $\mu=1,0 \pm 0,2$ (de acordo com dados da literatura $[7,16], 0,8 \leq \mu \leq 1,2)$.

A Figura 4 mostra uma planilha com os dados de entrada e os resultados obtidos, bem como o gráfico da velocidade x frequência em forma de sino (curva gaussiana). Verifica-se que há discrepância entre o valor obtido para a velocidade de projeção do motociclista imediatamente após o desprendimento $(45 \mathrm{~km} / \mathrm{h} \pm 5)$ e a velocidade desenvolvida pela motocicleta nos instantes imediatamente anteriores à colisão determinada por imagens de CFTV $(65 \mathrm{~km} / \mathrm{h})$. Esta discrepância decorre do fato de não se considerar a energia dissipada nos danos causados na motocicleta durante o desprendimento do motociclista. Havia um amassamento no tanque da motocicleta e o guidão sofreu um empenamento, ambos decorrentes da movimentação do corpo do motociclista durante o desprendimento. Em virtude disso, a fim de que o método mostrasse o valor da velocidade desenvolvida pela motocicleta nos instantes imediatamente anteriores à colisão, foi necessário admitir uma velocidade de danos da ordem de $47 \mathrm{~km} / \mathrm{h}$. Lembremos que essa velocidade de danos seria o equivalente à velocidade que o corpo do motociclista deveria desenvolver para causar na motocicleta os danos constatados.

Caso 02: A Figura 5 representa uma situação em que um veículo adentra a região do cruzamento e tem sua lateral posterior direita atingida por uma motocicleta que 


\begin{tabular}{|l|c|c|c|c|}
\hline \multicolumn{5}{|c|}{ DADOS DE ENTRADA } \\
\hline Altura do Centro de Massa no momento do lançamento & $h_{\circ}$ & 0,90 & \pm & 0,05 \\
\hline Distância entre o Ponte de Colisão e o ponto de repouso final & $\mathrm{S}_{t}$ & 18,0 & \pm & 0,5 \\
\hline Ângulo de lançamento & $\theta$ & 12,5 & \pm & 2,5 \\
\hline Ângulo de inclinação do terreno & $\alpha$ & 0,00 & \pm & 0,00 \\
\hline Coeficiente de atrito/arrasto (corpo flácido contra pavimento) & $\mu$ & 1,00 & \pm & 0,20 \\
\hline Velocidade de danos (corpo do motociclista contra a motocicleta) & $(\mathrm{km} / \mathrm{h})$ & 47,0 & \pm & 2,0 \\
\hline \multicolumn{2}{|c|}{ RESULTADOS } & & & \\
\hline Velocidade do motociclista imeditamente após o desprendimento & 45 & \pm & 5 \\
\hline Velocidade da motocicleta imediatamente antes da colisão & 65 & \pm & 4 \\
\hline Distância de voo & $\mathrm{S1}(\mathrm{m})$ & 10,0 & \pm & 1,8 \\
\hline Distância de deslizamento & $\mathrm{S} 2(\mathrm{~m})$ & 8,1 & \pm & 1,8 \\
\hline
\end{tabular}

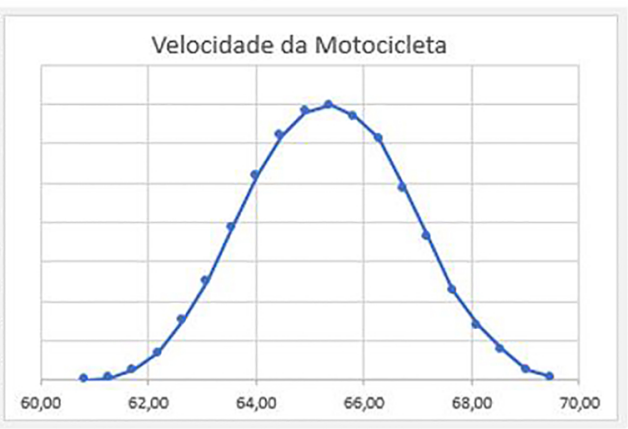

Figura 4: Resultado para o Caso 01 da velocidade desenvolvida pelo corpo do motociclista imediatamente após o desprendimento e da velocidade desenvolvida pela motocicleta imediatamente antes da colisão aplicando a metodologia proposta

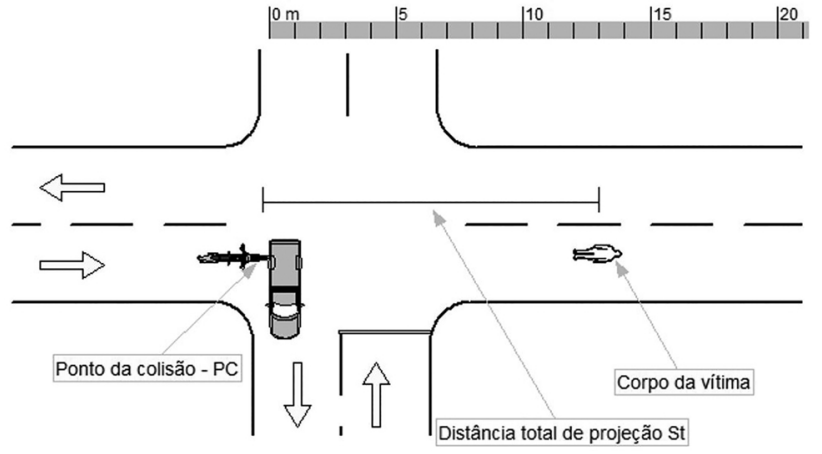

Figura 5: Esquema representativo de uma colisão envolvendo motocicleta e veículo com a projeção do corpo do motociclista (Caso 02)

trafegava pela via preferencial. Neste caso, a velocidade desenvolvida pelo veículo no momento da colisão era da ordem de $45 \mathrm{~km} / \mathrm{h}$. Entretanto, as imagens de CFTV recolhidas no local mostraram que este fato não influenciou significativamente na mudança de direção do movimento desenvolvido pelo motociclista. Assim como no Caso 01, a velocidade desenvolvida pela motocicleta nos instantes imediatamente anteriores à colisão foi calculada com base nas referidas imagens recolhidas no local e chegou-se a um valor da ordem de $60 \mathrm{~km} / \mathrm{h}$.

Os dados utilizados para o cálculo da velocidade da motocicleta pelo método que está sendo proposto são:

- Altura do centro de massa do motociclista no momento do lançamento: $h_{0}=0,85 \pm 0,05 \mathrm{~m}$ (dado estimado em função da altura da motocicleta, medido no local, e da altura do motociclista, obtido no Instituto Médico Legal);

- Distância total de projeção do motociclista: $S_{t}=$ $11,5 \pm 0,5 \mathrm{~m}$ (medido no local do acidente por peritos criminais);

- Ângulo de lançamento: $\theta=12,5^{\circ} \pm 2,5^{\circ}$ (de acordo com dados da literatura $[8,17]$, oscila entre $10^{\circ} \mathrm{e}$ $\left.15^{\circ}\right)$

- Ângulo de inclinação do terreno: $\alpha=0,0^{\circ} \pm 0,0^{\circ}$ (medido no local do acidente por peritos criminais);
- Coeficiente de atrito: $\mu=1,0 \pm 0,2$ (de acordo com dados da literatura $[7,16], 0,8 \leq \mu \leq 1,2)$.

Novamente, verifica-se na Figura 6 uma discrepância entre o valor da velocidade do motociclista nos instantes imediatamente após o desprendimento $(35 \mathrm{~km} / \mathrm{h} \pm 4) \mathrm{e}$ a velocidade desenvolvida pela motocicleta nos instantes imediatamente anteriores à colisão $(60 \mathrm{~km} / \mathrm{h}$, de acordo com imagens de CFTV). A fim de que o método mostrasse o valor da velocidade desenvolvida pela motocicleta nos instantes imediatamente anteriores à colisão, foi necessário, novamente, admitir uma velocidade de danos. Nesse caso o valor foi algo da ordem de $49 \mathrm{~km} / \mathrm{h}$, compatível com as avarias encontradas na estrutura da motocicleta, muito semelhante ao Caso 01 analisado.

\section{Conclusões}

O método físico proposto no presente trabalho é uma ferramenta alternativa que pode ser empregada no cálculo de velocidades de qualquer modelo de motocicleta. Devese observar, entretanto, que ele só é aplicável se não houver colisão entre o corpo do motociclista e outros objetos durante a fase de voo e/ou de deslizamento.

A energia dissipada nos danos causados na estrutura da motocicleta pelo corpo do motociclista durante o desprendimento não pode de maneira alguma ser desprezada. Nos dois casos estudados os valores ficaram bem próximos, $47 \mathrm{~km} / \mathrm{h}$ e $49 \mathrm{~km} / \mathrm{h}$, respectivamente. Ressalta-se, com isso, a necessidade de estudos aprofundados para se obter com a maior precisão possível o valor para a velocidade de danos, ou seja, valores de energia que o corpo do motociclista perde ao colidir com partes da motocicleta (por exemplo, ao amassar o tanque de combustível).

A aplicação do método de Monte Carlo à equação deduzida mostra uma curva gaussiana bem característica, o que indica compatibilidade entre os dois métodos.

No caso de colisões envolvendo motocicleta e outro veículo, a velocidade calculada para a motocicleta, por meio da presente metodologia, poderá servir de parâmetro de entrada para outros métodos a serem empregados no cálculo da velocidade do outro veículo. 


\begin{tabular}{|l|c|c|c|c|}
\hline \multicolumn{7}{|c|}{ DADOS DE ENTRADA } \\
\hline Altura do Centro de Massa no momento do lançamento & $\mathrm{h}_{0}$ & 0,85 & \pm & 0,05 \\
\hline Distância entre o Ponte de Colisão e o ponto de repouso final & $\mathrm{S}_{\mathrm{t}}$ & 11,5 & \pm & 0,5 \\
\hline Ângulo de lançamento & $\theta$ & 12,5 & \pm & 2,5 \\
\hline Ângulo de inclinação do terreno & $\alpha$ & 0,00 & \pm & 0,00 \\
\hline Coeficiente de atrito/arrasto (corpo flácido contra pavimento) & $\mu$ & 1,00 & \pm & 0,20 \\
\hline Velocidade de danos (corpo do motociclista contra a motocicleta) & $(\mathrm{km} / \mathrm{h})$ & 49,0 & \pm & 2,0 \\
\hline \multicolumn{2}{|c|}{ RESULTADOS } & & & \\
\hline Velocidade do motociclista imeditamente após o desprendimento & 35 & \pm & 4 \\
\hline Velocidade da motocicleta imediatamente antes da colisão & 60 & \pm & 4 \\
\hline Distância de voo & $\mathrm{S1}(\mathrm{m})$ & 6,7 & \pm & 1,1 \\
\hline Distância de deslizamento & $\mathrm{S} 2(\mathrm{~m})$ & 4,8 & \pm & 1,1 \\
\hline
\end{tabular}

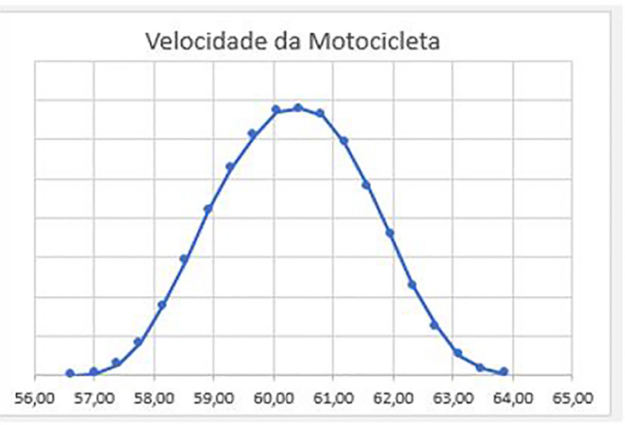

Figura 6: Resultado para o Caso 02 da velocidade desenvolvida pelo corpo do motociclista imediatamente após o desprendimento e da velocidade desenvolvida pela motocicleta imediatamente antes da colisão aplicando a metodologia proposta

\section{Agradecimentos}

Agradecemos à Fundação de Peritos em Criminalística Ilaraine Acácio Arce (FPCIAA) e à Fundação de Apoio à Pesquisa do Distrito Federal (FAP/DF) pelo apoio financeiro no projeto (bolsa de Iniciação Científica Edital 06/2018-FAP/DF). Gostaríamos, também, de deixar nossa gratidão ao Perito Criminal Rodrigo Franco Almeida pelo apoio nas análises de vídeos, ao Perito Criminal Charles Albert Andrade pela revisão do manuscrito e a todos os demais Peritos Criminais que direta ou indiretamente contribuíram para o desenvolvimento deste trabalho. Por fim, nosso agradecimento vai ao engenheiro Angel Antonio Montenegro pela iniciativa ousada em apresentar o seu método em 2014.

\section{Referências}

[1] Organização Pan-Americana da Saúde (OPAS) e Organização Mundial da Saúde (OMS), Folha informativa - Acidentes de trânsito, atualizado em fevereiro de 2019, disponível em: https://www.paho.org/bra/index.php?option= com_content\&view=article\&id=5147: acidentes-detransito-folha-informativa\&Itemid=779, acessado em 09/05/2020.

[2] A. Tonietto, B. Telles, C.A. Andrade, C.R. Dias Filho, E. Medeiros, J.A. Gomes e M.P.O. Valadares, Rev. Bras. Crimin. 2, 5 (2013).

[3] C.A. Andrade, J.L.S. Farias e J.A. Gomes, Rev. Bras. Crimin. 4, 7 (2015).

[4] W.X. Camargo Filho, B. Telles, C.A. Andrade, M.S. Sercheli, N.M. Kawano, R.M. Soares, A.N. Vicente, R.S. Corrêa e J.A. Gomes, Rev. Bras. Crimin. 5, 7 (2016).

[5] O. Svenson e I. Salo, Accid. Anal. Prev. 42, 704 (2010).

[6] H.Y. Lin, K.J. Lia e C.H. Changa, Image Vis. Comput. 26, 1327 (2008).

[7] J.J. Eubanks, Pedestrian Accident Reconstruction and Litigation (Lawyers and Judges Publishing Company, Tucson, 1999), $2^{\text {a }}$ ed., p. 1004.

[8] L.L. Almeida, Manual de perícias em Acidentes de trânsito (Millennium Editora, Campinas, 2015), $2^{\mathrm{a}}$ ed., p. 504 .
[9] O.N. Neto e R. Kleinübing, Dinâmica dos Acidentes de Trânsito: análises, reconstruçôes e prevenção (Millennium Editora, Campinas, 2009), $3^{\text {a }}$ ed., p. 314.

[10] J.M.H. Mota, Guía de investigación y reconstrucción de Accidentes de Tránsito Terrestre - evidencias criminalísticas y solución matemática (Flores Editor y Distribuidor, Cidade do México, 2016), $1^{\mathrm{a}}$ ed., p. 684.

[11] W.P. Gurgel, L.M. Gomes, F.C.L. Ferreira e R.M. Gester, Rev. Bras. Ensino Fís. 37, 4305-1 (2015).

[12] M. Batista, Promet - Traffic-Traffico 20, 357 (2008).

[13] D. Halliday, R. Resnick e J. Walker, Fundamentos de física: mecânica (Livros Técnicos e Científicos Editora, Rio de Janeiro, 2016), 10 a ed., v. 1, p. 797.

[14] J.A. Searle e A. Searle, SAE Technical Paper 831622 (1983).

[15] D. Wood e C. Simms, Impact 9, 12 (2000).

[16] L.B. Fricke, Traffic Crash Reconstruction (Northwestern University Center for Public Safety, Evanston, 2010), $2^{\mathrm{a}}$ ed., p. 824.

[17] G.L. Stephens, Formula workbook for traffic accident investigation and reconstruction (Institute of Police Technology and Management Publisher, Jacksonville, 2019), $2^{\mathrm{a}}$ ed., p. 314.

[18] W. Toresan Jr, em XXIV Congresso Nacional de Criminalística (Florianópolis, 2017).

[19] W. Wach e J. Unarski, em SAE 2006 World Congress \&6 Exhibition (Detroit, 2006). 